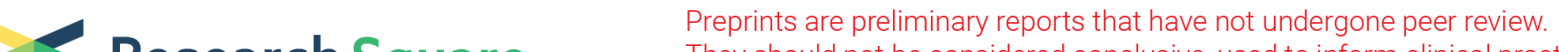 Research Square They should not be considered conclusive, used to inform clinical practice, or referenced by the media as validated information.
}

\section{Shaking Table Test and Numerical Simulation On Seismic Behavior of a Receiver Tower in Concentrated Solar Power Plant Under Vertical Earthquake}

Jiarui Li ( $\square$ lijiarui@xauat.edu.cn )

Xi'an University of Architecture and Technology https://orcid.org/0000-0002-9270-7219

Guoliang Bai

Xi'an University of Architecture and Technology

Bin Hao

Xi'an University of Architecture and Technology

Shengjie Peng

Xi'an University of Architecture and Technology

Yanyu Lang

Xi'an University of Architecture and Technology

Yazhou Xu

Xi'an University of Architecture and Technology

\section{Research Article}

Keywords: Receiver tower, Seismic behavior, Vertical earthquake, Shaking table test, Numerical simulation

Posted Date: October 25th, 2021

DOI: https://doi.org/10.21203/rs.3.rs-997778/v1

License: (1) This work is licensed under a Creative Commons Attribution 4.0 International License. Read Full License 


\section{Abstract}

The solar receiver tower is a new type of high-rise power generation structure, which has been constructed and applied in a small amount around the world in recent years. To understand its seismic behavior under vertical earthquakes, a 1/18 reduced scale model structure was designed and investigated by shaking table test. The El-Centro wave, Taft wave and Artificial wave were input as the earthquake excitation. This paper summarized the results of the experimental work, which could provide an important theoretical basis for evaluating the seismic behavior of receiver tower under vertical earthquakes. The damage distribution, dynamic characteristics, acceleration responses, displacement responses and vertical seismic force were analyzed quantitatively. In addition, a numerical simulation model of the receiver tower was established, and nonlinear time-history analysis was then conducted by using the software ABAQUS. The results between the experimental test and the numerical simulation were compared and they were in good agreement. Both of experimental and numerical simulation results showed that the model structure was subjected to huge vertical seismic force in the middle part of concrete cylinder under vertical earthquakes with high PGA, which caused severe damage and should be paid more attention in seismic design. Despite the serious damage and complex earthquake responses, combined with experimental test and simulation results, the seismic behavior of structure under vertical earthquake is good and generally satisfactory.

\section{Introduction}

Solar energy has become a hot spot of current research because of its richness, safety and cleanliness (Lotfabadi et al. 2015). One of the significant uses of solar energy is power generation, which can effectively alleviate the global energy crisis (Azoumah et al. 2010). Tower-type concentrated solar power has the advantages of large capacity, low cost, small heat loss, and excellent power quality, therefore it has been gradually applied at home and abroad(Dominik et al. 2010; Zare et al. 2016; leva et al. 2020). The solar receiver tower is the core structure of concentrated solar power plant, which is not only a type of tower structure but also a high-rise industrial building. The shape of receiver tower looks like reinforced concrete chimney structure to some extent, but they are different in many aspects. First, the receiver tower consists of reinforced concrete cylinder and steel truss, it belongs to a vertical steel-concrete hybrid structure. The difference of material properties makes the stiffness of the connection part between steel structure and concrete cylinder suddenly change, which may cause serious whiplash effect in the top of tower. Next, in order to meet the power generation requirements, many platforms and power generation equipment are arranged inside the receiver tower, it makes the structure more complicated and more easily to be damaged or even collapse under earthquakes. On the other hand, as a lifeline project, the safety of receiver tower is higher than that of the common structure, so the design indexes such as displacement, inclination and settlement are strictly required (Behar et al. 2013).

In previous study, most of the researchers mainly focused on the seismic performance of high-rise tower structures under horizontal earthquakes (Zhang et al. 2018; Lu et al. 2013; Hariri-Ardebili et al. 2014; Guo et al. 2019), while little study were related to the seismic performance under vertical earthquakes. Some special structures such as high-rise buildings, towers and bridges are more likely to be damaged under vertical earthquake (Furukawa et al. 2013; Abdollahiparsa et al. 2016; Harrington et al. 2016). Therefore, this paper focuses on the seismic behavior of solar receiver tower under vertical earthquakes. 
The earliest research on vertical ground motion began with the investigation and analysis of earthquake damage. The investigation of the Hanshin Earthquake in Japan in 1995 (Bruneau et al. 1998; Scawthorn et al. 1995) and the Turkish Earthquake in 1998 (Adalier et al. 2001; Sezen et al. 2003; Doğangün et al. 2003) showed that many structural damage and collapse were not caused by horizontal earthquake, but by vertical earthquake, which led to researchers paid more attention to the vertical seismic response of the structure once more. At first, an orthogonal set of principal axes for earthquake ground motions (Penzien et al. 1974) was put forward, then the vertical ground motions and damage effects on structure were studied ( Lin et al. 1981 and Lin et al. 1982; Elnashai et al. 1996 and Elnashai et al. 1997; Button et al. 2002; Elgamal et al. 2004), they confirmed that structural failure may be caused by direct tension or compression as well as due to the effect of vertical motion on shear and flexural response. To take the vertical acceleration component in the current methods of seismic action into account and fill in the lack of seismic specification, the horizontal and vertical earthquakes were compared (Sarno et al. 2011; Bozorgnia et al. 2016) and vertical-to-horizontal (V/H) ratios of PGA was analyzed (Miguel et al. 2019). These theoretical studies had laid a theoretical foundation for the subsequent experimental research under the action of vertical earthquakes. The seismic response of masonry structures and reinforced-concrete frames under vertical earthquakes were studied (Rinaldin et al. 2019; Felice et al. 2020), the results showed not only variance of the vertical ground motion, but also cross-covariance with the horizontal one should be considered in the near field. The fracture phenomenon of a 180m RC chimney and a $45 \mathrm{~m}$ brick chimney subjected to vertical seismic action by carrying out a shaking table test (Chen et al. 2005) were investigated and analyzed the test results by using wave theory. It indicated that the maximum vertical strain varied along the height of chimney with the increasing of seismic intensity, and the necessity of taking vertical seismic action into account in high-rise structure design was emphasized. A shaking table test (Jin et al. 2012) has been conducted to study the vertical seismic responses of a quayside container crane, and the modeling method about numerical simulation was put forward, the experimental results were compared with the numerical analysis and agreed fairly well. The shaking table test (Yu et al. 2014) of a largespan station hall was to carried out understand its dynamic response characteristics and yielding mechanism under different levels' vertical earthquake excitation. The studies mentioned above had provided precious information about vertical earthquake for this research, such as the test method and modeling method, but the tested structures were not tower structure, and their seismic responses were different.

With the development of the industry, tower structures are widely used around the world. It is important to study the seismic response of tower structures. Many of researchers (Sami et al. 2018; Polyzois et al. 2009; Yu et al. 2016; Huang et al. 2010; Pratesi et al. 2014; Gurkalo et al. 2017; Piotr et al. 2018) have studied the tower structures by experimental test and numerical analysis. All the results confirmed the impact of horizontal earthquakes, and the seismic responses were analyzed deeply. However, few of these studies presented the results of seismic responses under vertical earthquakes. For the above reasons, it is necessary and important to study the seismic responses of the solar receiver tower under vertical earthquakes. In this paper, a high-rise steel-concrete hybrid model structure of solar receiver tower was selected to analyze the dynamic characteristics and seismic response by shaking table test and numerical simulation. A 1/18 reduced scale model structure was designed and investigated, the El-Centro wave, Taft wave and Artificial wave were input as the earthquake excitation. This paper summarized the results of the experimental work and established the numerical simulation model of the receiver tower. The results between the experimental test and the numerical 
simulation were compared and they were in good agreement. This paper could provide important reference for evaluating the seismic behavior and the seismic design of receiver tower under vertical earthquakes.

\section{Shake Table Test Setup}

\subsection{The prototype structure}

The prototype structure is a high-rise solar receiver tower located in a concentrated solar power plant, which has been used to power generation now (Fig. 1(a)). The total height of the receiver tower is $243 \mathrm{~m}$, and it consists of the reinforced concrete cylinder $(200 \mathrm{~m})$ and the steel truss $(43 \mathrm{~m})$. The bottom diameter of the reinforced concrete cylinder is $23 \mathrm{~m}$ and the top diameter is $20 \mathrm{~m}$. The elevation and section views are shown in Fig. 1(b).

\subsection{Similarity design}

The similarity ratios are one of the most important parameters in the shaking table test. In order to ensure the experimental results of the model structure accurately reflect the seismic performance of the prototype structure, the similarity ratios between the model structure and the prototype structure should be satisfied as much as possible. However, it is difficult to satisfy the similarity relationship of all physical quantities in a reduced scale model experiment. Generally, there are 3 controlling similarity ratios: length, stress, and acceleration in a shaking table test according the similarity law (Harris et al. 1983). The remaining similarity constants could be obtained according to quasi-dimensional analysis (Zhou et al. 2012). Considering the laboratory space and the capacity of the shaking table, the length similarity ratio is selected as $1 / 18$; the lead powder microconcrete is used to replaced the ordinary concrete in the prototype structure, and its stress and elastic modulus are $1 / 3$ of the prototype; the acceleration similarity ratio is decided to be 2.25 in order to avoid the insufficient inertia force. The rest of similarity ratios are calculated according to the quasi-dimensional analysis method, as shown in Table 1.

\subsection{Materials}

The scaled model structure is relatively small and can not be built using the materials in the prototype structure, so the lead powder micro-concrete, galvanized iron wire and red copper are selected to replace the ordinary concrete, rebar and steel in the prototype structure respectively. According to material experimental test, the material properties are obtained as summarized in Table 2. There is a certain error between the actual value and the design value of the stress and elastic modulus of the materials, but considering some influence factors such as the special structure system, complex construction technology and the quality of the model, the similarity ratios of $1 / 3$ of the stress and elastic modulus are acceptable in the test.

\subsection{Design and construction of model structure}

The simplified design of the model structure should follow the similarity law, and the scale design of the prototype structure should be carried out according to the similarity ratios, so that the test results can reckon the seismic performance of the prototype structure without much error. In fact, it is usually necessary to consider many factors such as the size of the test site and the construction environment, and then simplify or 
even ignore some secondary factors. The concrete cylinder of the model structure is designed based on the geometric similarity relationship, and the dimensions of the concrete cylinder are shown in Fig. 2 and Table $\mathbf{3}$. According to the similarity of bearing capacity (Lu et al. 2012), the simplified design of the longitudinal reinforcement and the circumferential reinforcement was carried out separately, it is summarized in Table 4 and shown in Fig. 3-4. The steel truss of prototype structure is simplified according to the equivalent lateral stiffness. The simplified copper truss structure and member types are displayed in Fig. 5-6.

The total height of the model structure is $13.980 \mathrm{~m}$ (excluding $0.4 \mathrm{~m}$ of the base), where the concrete cylinder is $11.290 \mathrm{~m}$ and the copper truss is $3.1 \mathrm{~m}$ (including the connection part). The total weight of the model structure is about $14.56 \mathrm{t}$, which meets the requirement of the mass similarity ratio. The copper truss and the overall overview of the model are shown in Fig. 7-8.

\subsection{Seismic waves and test conditions}

The prototype structure is located in class $\otimes$ site and 7 degree seismic fortification. According to the selection requirements of the ground motions, combined with the Chinese specification( Code for seismic design of buildings GB 50009-2012 and Specification for seismic test of buildings JGJ/T 101-2015), at least 3 ground motions including two natural and one artificial ground motions should be selected as the input seismic waves of the shaking table test. In this experimental test, two natural waves (El-Centro wave and Taft wave) were selected. The El-Centro wave: recorded from the Imperial Valley Earthquake (18, May, 1940). Taft wave: recorded from the Lincoln School Tunnel site in California during the Taft Earthquake (21, July, 1952). An artificial wave was fitted according to the response spectrum characteristics of the class $\nabla$ site. The amplitude, frequency spectrum characteristics and duration time are the three main parameters of ground motion. All the waves for tests were corrected by the SeismoSignal software according to similarity principle. It is necessary to correct the amplitude, frequency and the duration time of these seismic waves so as to meet the similarity law. For example, the amplitude that also called the peak ground acceleration (PGA) in the test is equal to the peak value given by the Chinese specification multiplied by the acceleration similarity coefficient of 2.25 . The input amplitude ratio of ground motion in different direction is 1 ( $X$ direction) : 0.85 ( $Y$ direction) : 0.65 ( $Z$ direction). All the seismic waves were well fitted with the design response spectrum, Fig. 9-10 display the seismic waves and their acceleration response spectrum.

Before and after each loading condition, white noise $(P G A=0.030 \mathrm{~g})$ test was performed to study the dynamic characteristics of the model structure. The main research purpose of the paper is to study the seismic behavior of the receiver tower under vertical earthquake, therefore, in most conditions only $Z$ direction seismic waves were input. In rare earthquake of 8 degree stage, three direction seismic waves were input in order to compare the vertical and horizontal earthquake response. The specific test conditions are shown in Table 5.

\subsection{Shaking table and measuring points}

The shaking table test was carried out on the three directions earthquake simulation device in the Key Laboratory at Xi'an University of Architecture and Technology, Shaanxi Province, China. The parameters of the shake table are listed in Table 6. 33 acceleration sensors and 30 strain gauges were placed in the model structure in order to get the earthquake responses of the model conveniently.Fig .11 shows the layout of these measuring points. 


\section{Test Results And Analysis}

\subsection{Test phenomenon}

The the PGA of $0.113 \mathrm{~g}$ in Z direction: In the fortification earthquake of 6 degree stage, El-Centro wave, Taft wave and Artificial wave were input according to loading sequence. In the test process, the vibration of the whole model was very small, and no visible crack was found on the surface of the concrete cylinder, all the members of the copper structure did not buckle and no obvious deformation. The experimental phenomena showed that the model structure was in the elastic stage under fortification earthquake of 6 degree.

The the PGA of $0.158 \mathrm{~g}$ in $Z$ direction: In the frequent earthquake of 8 degree stage, El-Centro wave, Taft wave and Artificial wave were input according to loading sequence. The overall vibration of the model structure was obvious, some micro-cracks were formed on the surface of the concrete cylinder, and all the cracks appeared at the height of $0-2 \mathrm{~m}$, as shown in Fig. 12. Most of them were horizontal and several were diagonal, the length and width of every micro-crack was short and narrow, and all of the cracks were discontinuous. In the meanwhile, no visible local buckling or damage occurred in the copper structure. The white noise test showed that the vertical natural frequency of the model structure was attenuated slightly, but the reduction was small, which indicated the model structure was still in elastic stage, or may reach the edge of the elastic stage.

The the PGA of $0.225 \mathrm{~g}$ in $Z$ direction: In the fortification earthquake of 7 degree stage, El-Centro wave, Taft wave and Artificial wave were input according to loading sequence. The vertical amplitude of the model structure increased significantly, the vertical cracks appeared near the opening at the bottom of the model, and a series of cracks developed near $6-7 \mathrm{~m}$ of the concrete cylinder, some of them extended to $300 \mathrm{~mm}$, as shown in Fig. 13. There was no obvious local buckling or damage occurred in the copper structure, which indicated the copper structure still kept good performance. The vertical natural frequency of the structure decreased further after white noise test, the results showed that the concrete cylinder may enter the elastic-plastic stage.

The the PGA of $0.900 \mathrm{~g}$ in three directions (X: $Y: Z=1.00: 0.85: 065)$ : In the rare earthquake of 8 degree stage, El-Centro wave, Taft wave and Artificial wave were input according to loading sequence. Under the action of three-way seismic waves, the overall model shaked violently and the seismic responses were strong. The cracks at the $3 \mathrm{~m}$ and $7 \mathrm{~m}$ of the concrete cylinder continued to develop into horizontal circumferential cracks, the length and the width of the horizontal circumferential cracks were almost up to $3.5 \mathrm{~m}$ and $0.8 \mathrm{~mm}$ respectively (Fig. 14). Many new cracks appeared on the surface of the concrete cylinder due to the action of horizontal earthquake. In the copper structure, some columns and diagonal braces buckled, the overall stability reduced because of the buckling of members. But no visible deformation appeared in the horizontal beam, which meant the seismic responses of beam was small. By the white noise test, the natural frequency of model structure attenuated greatly, which indicated the stiffness of the model structure decreased at this time. Furthermore, the model did not collapse under high intensity earthquakes, it still remained bearing capacity.

\subsection{Dynamic characteristics}

Before and after each test stage, white noise test was carried out on the model structure to obtained the natural frequencies and damping ratios (Table 7) calculated by the transfer function and the half-power bandwidth method (Papagiannopoulos et al. 2011). To quantitatively analyze the change of stiffness, the 
stiffness degradation coefficient $\eta$ can be defined based on Equation (1) and (2). The first order mode factor can be obtained by normalizing the maximum displacement vector. Based on the mode factor, the first-order mode shape in vertical is shown in Fig. 15.

$$
\begin{aligned}
& f=\left(\frac{1}{2 \pi}\right) \sqrt{\frac{k}{m}}(1) \\
& \eta=\frac{k-k_{0}}{k_{0}}=\frac{f^{2}-f_{0}^{2}}{f_{0}^{2}}
\end{aligned}
$$

Where: $k_{0}$ is the initial stiffness of the model, and $k$ is the stiffness at the end of each loading condition; $m$ is the total mass; $f_{0}$ is the initial natural frequency, and $f$ is the natural frequency at the end of each loading condition.

The first-order natural frequency in vertical of the model structure is relatively large, which is also in line with the general characteristics of high-rise structures: the vertical stiffness is significantly large, and the vertical vibration is close to high-frequency vibration ( $\mathrm{Li}$ et al. 2011). With the increase of PGA, the vertical natural frequencies of the model structure gradually decreases. Before the PGA of $0.225 \mathrm{~g}$ was input, the natural frequencies decreased slowly, and it begun to reduce quickly after the fortification earthquake of 7 degree stage. The reason is that no damage occurred on the model structure or the damage was not severe before the PGA of $0.225 \mathrm{~g}$, while the damage became serious after the PGA of $0.225 \mathrm{~g}$ was input. After the test, the vertical natural frequencies of first three orders of the model structure reduced to $16.04 \mathrm{~Hz}, 17.38 \mathrm{~Hz}$ and $18.33 \mathrm{~Hz}$ respectively, which were decreased by $13.5 \%, 13.6 \%$ and $17.2 \%$ compared with the frequency before the test. The damping ratio increased gradually with the increase of PGA, especially after the input of the three dimensional seismic waves, the damping ratio increased from 0.045 to 0.096 , which exceeded 0.005 that is damping ratio of RC structure defined in Chinese specification (Load code for the design of building structures GB 50009-2012). Due to the damage of the model structure, the stiffness gradually decreased, and it decreased by $25.23 \%$ until the test was finished. Under the vertical earthquake, the vibration of the model structure is axial, it causes the vertical seismic force in model. The concrete cylinder is subjected to compression or even tensile stress, which results in horizontal circumferential cracks appear at the height of $3 \mathrm{~m}$ and $7 \mathrm{~m}$, indicating that the two sections are dangerous part of the model structure.

\subsection{Acceleration response}

By analyzing the acceleration response at each measuring point of the model structure, the maximum acceleration at different heights under different PGA was obtained (Table 8). The acceleration amplification factors of the model structure under each working condition were further calculated by Equation (3), which is the ratio of the measured peak acceleration to the same direction peak acceleration at the base. It is an important indicator of the dynamic response of the model structure.(Fig. 16).

$$
\beta_{i}=\frac{a_{i, \max }}{a_{0, \max }}
$$

Where: $\beta_{i}$ is the acceleration amplification factor at different height, $a_{i, \text { max }}$ is the maximum acceleration at measuring point, $a_{0, \text { max }}$ is the maximum acceleration of the shaking table. 
Table 8 lists the maximum acceleration of model structure under different PGA. With the increase of PGA, the maximum acceleration also increase. Under the action of different PGA $(0.113 \mathrm{~g}, 0.158 \mathrm{~g}, 0.225 \mathrm{~g}, 0.900 \mathrm{~g})$, the average maximum acceleration are $0.401 \mathrm{~g}, 0.519 \mathrm{~g}, 0.713 \mathrm{~g}$ and $1.979 \mathrm{~g}$, respectively. The receiver tower model consists of concrete cylinder and copper truss, but the acceleration responses of the two substructures are quite different. Under the same earthquake, the acceleration response of the copper structure is smaller than that of the concrete cylinder (Fig. 16), this is may attribute to the vertical whiplash effect that could reduce the acceleration response of copper structure.

The acceleration response of the concrete cylinder: Acceleration reaches the maximum value at the height of 2-8m under all seismic waves. Meanwhile the acceleration amplification factors under the artificial waves are the largest among the three seismic waves, indicating that different types of seismic waves have different effects on the structural response. As the PGA of the input seismic waves gradually increase, there is no obvious change of the envelope diagrams of acceleration amplification factor, which has rarely been found in previous studies. As can be seen, $\beta$ is the ratio of the PGA at measuring points to the PGA at the base, it is possible to present the same value under vertical earthquake. Under the PGA of $0.113 \mathrm{~g}, 0.158 \mathrm{~g}, 0.225 \mathrm{~g}$, all of the acceleration amplification factors are less than 1.0 at the height of $11 \mathrm{~m}$, while it is larger than 1.0 with the PGA of $0.900 \mathrm{~g}$. It shows that the acceleration response at the top of concrete cylinder is enhanced under the vertical earthquakes with high PGA. The acceleration response of copper structure: Under low seismic intensity, with the PGA increases, the acceleration amplification factors decreases, and it reduces to the minimum values when the PGA is $0.225 \mathrm{~g}$. But under high seismic intensity, for example, with the PGA of $0.900 \mathrm{~g}$, the acceleration amplification factor of the copper structure is close to that of the concrete cylinder, the reason may be that the artificial mass on the copper structure increases the seismic response when subjected to vertical earthquakes with high value of PGA.

In term of the change rule of acceleration response, the two substructures are the same. That is, the acceleration response increases first and then decreases gradually along the height, and the turning point of acceleration is located at the $2 / 3$ height of the respective substructures, in which the acceleration response of concrete cylinder starts to decrease at the height of $8 \mathrm{~m}$, and the copper structure begins to decrease at the height of $12.5 \mathrm{~m}$. It indicates the range that from the height of $1 / 3$ to $2 / 3$ of each structure is the concentrated area of seismic response, which should be strengthened in seismic design.

\subsection{Displacement response}

Based on the second integration of the acceleration time history response measured by the acceleration sensor, the maximum displacement of the model structure at different height relative to the base under different levels of earthquakes can be obtained (Table 9). To analyse the displacement response better, the vertical displacement envelope diagrams are shown in Fig. 17.

Table. 9 and Fig. 17 show that with the increases of the PGA, the maximum displacement gradually increases, especially when the PGA is $0.900 \mathrm{~g}$, the displacement is almost twice compared with that of the PGA of $0.225 \mathrm{~g}$. The displacement response of the model structure reaches its maximum at the height of $4 \mathrm{~m}$, and the maximum vertical displacement is $4.96 \mathrm{~mm}$ under the artificial wave. In view of the overall model, displacement response of concrete cylinder is larger than that of copper structure, and the displacement response is generally larger in the range from $4 \mathrm{~m}$ to $7 \mathrm{~m}$, which shows that the displacement response of the 
model structure under vertical earthquake is mainly concentrated in the concrete cylinder. That may account for the severe damage of the model at the height of $3 \mathrm{~m}$ and $7 \mathrm{~m}$, which is consistent with the test

phenomenon. But generally speaking, the vertical displacement response of the model structure is always at a low level, indicating that the axial deformation of the model is not obvious under the vertical earthquakes. The displacement response of the connection part between copper structure and concrete cylinder is almost the same, which shows that the connection is reliable and the performance is good.

The displacement response characteristics of the concrete cylinder are similar to that of the acceleration responses, that is to say, the displacement response increases first along the height and then decreases gradually. The displacement turning point is located at the $2 / 3$ height of the concrete cylinder, and the displacement begins to decrease at $7 \mathrm{~m}$, illustrating the range of concentration area of the displacement response, which should be paid more attention. The vertical displacement of the copper structure is relatively small, and it is so tiny that can be neglected compared with the deformation ability of copper material.

\subsection{Vertical seismic force}

According to the acceleration response and structural mass distribution of the model structure, the vertical seismic force of the model structure under different levels of earthquakes is calculated. The specific results are shown in Table 10, and the envelope diagram of the vertical seismic force is depicted in Fig. 18.

Fig. 18 shows the vertical seismic force increases with the increase of PGA. Under different PGA action, the maximum vertical seismic force occurs at the height of $2 \mathrm{~m}$. The main reason is that both of the acceleration and mass distribution are the largest at this position. It gradually decreases along the height and reduces to the minimum at the top of tower. Under the action of seismic waves with the PGA of $0.900 \mathrm{~g}$, the maximum vertical seismic force of the concrete cylinder at the height of $2 \mathrm{~m}$ is $145.6 \mathrm{kN}$, which is about 18 times compared with the maximum vertical seismic force of the copper structure whose maximum value is $7.8 \mathrm{kN}$ at the height of $12.5 \mathrm{~m}$. As shown in Fig. 18, the vertical seismic force of the model structure is mainly concentrated within the height of $2 \mathrm{~m}-8 \mathrm{~m}$. This is because the vertical acceleration and mass distribution change along the model structure, causing the vertical seismic force to show the above-mentioned change trend. The damage of the concrete cylinder is also concentrated in this area, and the vertical seismic force is considered as the reason of structural failure.

\section{Analysis Of Numerical Simulation}

In order to verify the vertical earthquake responses of the shaking table test on the receiver tower model structure, a finite element model of the receiver tower was established with the widely used ABAQUS software. The S4R shell element and B31 beam elements were used in concrete cylinder and copper truss structure respectively. The constitutive relation of the lead powder concrete is shown in Fig. 19 (a) and (b) based on the Concrete Damage Plasticity Model. The ideal elastic-plastic model is used to define the copper members and galvanized wire, as shown in Fig. 19 (c). The parameters of the Concrete Damage Plasticity model and other material parameters are set in Table 11. The total nodes of the receiver tower finite element model are 6383, and the number of the elements is 6592, including 4288 B31 elements and 2304 S4R shell elements. Fig. 20 shows the whole receiver tower finite element model established in ABAQUS. 


\subsection{Dynamic characteristics of numerical model}

The first three natural frequencies of experimental and numerical model are summed up in Table 12. The first natural frequency between experimental and numerical model are very close, their corresponding values are $18.55 \mathrm{~Hz}$ and $19.06 \mathrm{~Hz}$ respectively, the error is only $2.7 \%$. Moreover, the errors of the second and third frequency between experimental and numerical model are $6.0 \%$ and $6.8 \%$ respectively. It shows that the experimental results are agree well with simulation results, which verifies the established numerical model could reproduce the earthquake responses of the receiver tower. Fig. 21 shows the first vibration mode shape of the numerical model.

\subsection{Time-history analysis of numerical model}

The time-history analysis of numerical model was carried out with the three seismic waves that used in the shaking table test, and all the test conditions were also conducted in numerical model. Based on the experimental results, the earthquake responses under the artificial wave are relatively large among the three seismic waves. Besides, there is limited to the article length. Therefore, only the earthquake responses under the artificial wave with PGA of $0.158 \mathrm{~g}$ and $0.900 \mathrm{~g}$ are shown in this part.

The comparison of acceleration time-history curves between experimental and numerical simulation at the height of $4 \mathrm{~m}$ are shown in Fig. 22. The difference of acceleration responses are minor, and the appearance time of peak acceleration is very close. It is indicated that the results of simulation are consistent with the experimental test. The errors of acceleration responses between experimental and numerical simulation are calculated, and the maximum errors of acceleration between experimental and numerical simulation with PGA of $0.158 \mathrm{~g}$ and $0.900 \mathrm{~g}$ are $6.1 \%, 14.7 \%$ respectively. Fig. 23 shows the comparison of vertical displacement time-history curves between experimental and numerical simulation at the height of $4 \mathrm{~m}$. With the PGA of $0.158 \mathrm{~g}$, the appearance time corresponding to the peak displacement of the simulation is slightly different with the experimental test, which is earlier than the experimental test. Whereas under the PGA of $0.900 \mathrm{~g}$, the appearance time of the peak displacement of the simulation coincides with the test. The peak displacement of the simulation is less than the test value under all conditions, which is considered to be the accumulated damage of the receiver tower in shaking table test and it does not be taken into consideration in the numerical simulation model. The maximum errors of vertical displacement between experimental and numerical simulation with PGA of $0.158 \mathrm{~g}$ and $0.900 \mathrm{~g}$ are $6.3 \%, 16.3 \%$ respectively.

The comparison of the time-history curves of vertical seismic force at the height of $2 \mathrm{~m}$ under the three seismic waves with the PGA of $0.900 \mathrm{~g}$ are shown in Fig. 24. The appearance time of peak value of time-history curves of simulation is highly consistent with the test value, while it can be seen that the peak vertical seismic force of simulation is slightly smaller than that of the experimental test. The average value of vertical seismic force under the artificial wave is the largest among the three seismic waves. The maximum errors of vertical seismic force between experimental and numerical simulation are $11.1 \%$. It is considered that time-history curves of simulation model basically coincides with the test model.

\subsection{Damage patterns of numerical model}


The result of numerical simulation model damage distribution is highly consistent with the test result, there is no observable damage under the PGA of $0.113 \mathrm{~g}$ and little damage occurs under the PGA of $0.158 \mathrm{~g}$. In this paper, the damage distribution and stress nephogram of the numerical model with the PGA of $0.225 \mathrm{~g}$ and $0.900 \mathrm{~g}$ are presented in Fig. 25. It shows that the obvious damage firstly appears at the lower part and the middle section of the numerical model, with the PGA increases, the damage of the numerical model becomes severe. From Fig. 25(c), it can be seen that the damage in bottom, $3 \mathrm{~m}$ and $7 \mathrm{~m}$ of the numerical model, which coincides with the damage distribution of the test model and the damage in bottom of the model may be caused by the horizontal earthquake. The stress nephogram shows that the stress is relatively large below $8 \mathrm{~m}$, and the peak values appear at the damage area. Generally speaking, the numerical simulation agrees well with the experimental results.

\section{Comparative Analysis Of Vertical And Horizontal Earthquake Action}

The maximum horizontal and vertical acceleration are obtained under the action of seismic waves with the PGA of $0.900 \mathrm{~g}$ (Fig. 26). It shows that the vertical acceleration of the concrete cylinder is much larger than that of the horizontal acceleration. $C$ is defined as the seismic action control coefficient, whose value is the ratio of horizontal shear force to vertical seismic force, as shown in Equation (4) and (5). When $C$ is less than 1 , vertical earthquakes play the control role in structural seismic responses, and the vertical earthquakes control effect decrease with the increase of $C$, whereas $C$ is greater than 1 , the horizontal earthquakes play the control role in structural seismic responses, and the horizontal earthquakes control effect increase with the increase of C. Table 13 shows the horizontal shear force of the model structure and the seismic action control coefficient $C$. As can be seen, in the range of $2 \mathrm{~m}-8 \mathrm{~m}$ of the concrete cylinder, the vertical seismic force is much larger than the horizontal shear force and the average value of the horizontal shear force is about $42.3 \%$ of the vertical seismic force, which indicates that the failure and damage at the middle position of the concrete cylinder is controlled by the vertical earthquakes. While at the base of the model structure, the steel-concrete connection part, and the copper structure, the average value of the horizontal seismic force is about 1.39 times to the vertical seismic force, demonstrating that and the horizontal seismic action definitely plays the control role in these parts.

$$
\begin{gathered}
C_{\mathrm{X}}=\frac{F_{\mathrm{X}}}{F_{\mathrm{Z}}} \\
C_{\mathrm{Y}}=\frac{F_{\mathrm{Y}}}{F_{\mathrm{Z}}}
\end{gathered}
$$

Where: $C_{\mathrm{X}}, C_{\mathrm{Y}}$ is the seismic action control coefficient in $\mathrm{X}$ and $\mathrm{Y}$ direction; $F_{\mathrm{X}}, F_{\mathrm{Y}}, F_{\mathrm{Z}}$ is the seismic force in $\mathrm{X}, \mathrm{Y}$, and $Z$ direction.

In order to study the influence of vertical seismic action on the structure, this paper uses finite element analysis to calculate the horizontal acceleration, horizontal displacement and bottom shear force of the model structure under the participation of vertical seismic. Compared with the seismic responses under horizontal seismic action, the seismic responses of the model structure under the $\mathrm{XZ}$ two-way earthquakes are greater than that 
of horizontal earthquakes, as shown in Table 14. The increment of those seismic responses under XZ two-way earthquakes are provided in Fig. 27.

When PGA is $0.225 \mathrm{~g}$, the top horizontal acceleration, displacement and bottom shear force of the model structure under $X Z$ bidirectional earthquake action are increased by $2.20 \%, 11.30 \%$ and $2.50 \%$ respectively compared with those under single horizontal earthquake action. It shows that the vertical seismic action has a obvious influence on the displacement of the structure. When PGA is $0.495 \mathrm{~g}$, the top horizontal acceleration, displacement and bottom shear force of the model structure under XZ bidirectional earthquake action are increased by $19.50 \%, 44.70 \%$, and $9.30 \%$ respectively compared with those under single horizontal earthquake action. At this time, the structural responses generally increase, indicating that the influence of vertical earthquakes on the structure is further strengthened, especially in terms of structural displacement and shear force. When PGA is $0.900 \mathrm{~g}$, the top horizontal acceleration, displacement and bottom shear force of the model structure under $X Z$ bidirectional earthquake action are increased by $22.72 \%, 55.50 \%$, and $20.10 \%$ respectively. The influence of vertical earthquake on the seismic response of the structure reaches the maximum, especially on the horizontal displacement. Therefore, the vertical earthquake action makes the structure more sensitive to the horizontal seismic action, and the vertical seismic action can not be neglected.

\section{Conclusions}

The solar receiver tower is a high-rise steel-concrete hybrid structure, which is also sensitive to vertical earthquake. To study its vertical earthquake responses and ensure its safety, shaking table test of a 1/18 scaled model structure was carried out, a series of vertical seismic waves were adopted to investigate the dynamic characteristics and seismic responses including acceleration and displacement. Moreover, a numerical simulation model of the receiver tower was established to verify the experimental results. The main conclusions of this paper were as follows:

(1) Damage distribution: Vertical cracks appeared near the opening at the bottom of the model, and a series of cracks developed near 6-7m of the concrete cylinder under the action of vertical earthquakes with the PGA of $0.225 \mathrm{~g}$. The cracks developed rapidly due to the participation of horizontal earthquakes when the seismic waves with the PGA of $0.900 \mathrm{~g}$ were input, horizontal circumferential cracks occurred at the height of $3 \mathrm{~m}$ and $7 \mathrm{~m}$. The columns and diagonal braces of copper structure were subjected to large forces with the PGA of $0.900 \mathrm{~g}$, which caused buckling of members.

(2) Dynamic characteristics: The first three vertical natural frequencies of the model structure were $18.55 \mathrm{~Hz}$, $20.12 \mathrm{~Hz}$ and $22.14 \mathrm{~Hz}$, respectively. It showed that the vertical vibration was closed to the high-frequency vibration. With the increase of PGA, the vertical natural frequency decreased gradually, and the damping ratio increased that varied from $4.5-9.6 \%$. In the meantime, the stiffness also reduced because of the damage in model structure, and it was almost decreased by $25.23 \%$.

(3) Seismic responses: Under the vertical earthquake, the acceleration response at the height of 2-8m of the concrete cylinder was larger than any other parts of the model structure. The vertical displacement was also concentrated at the middle part, it reached peak value at the height of $4 \mathrm{~m}$, which was the mass center of the concrete cylinder. The seismic responses of the concrete cylinder were larger than that of copper structure, but 
they presented the same rule that seismic responses increased quickly and then decreased gradually along the height direction with the increase of PGA.

(4) Seismic forces: With the increase of PGA, the vertical seismic force also increased. In the range of $2 \mathrm{~m}-8 \mathrm{~m}$ of the model structure, the vertical seismic force was far greater than the horizontal shear force under the seismic waves with the PGA of $0.900 \mathrm{~g}$, while the horizontal shear force was larger than the vertical seismic force in other parts. The control coefficient of seismic action was calculated, which indicated that the vertical earthquake caused the damage of the concrete cylinder in the middle part, and the horizontal earthquake caused the damage of other parts.

(5) Numerical simulation: Time-history analysis of earthquake responses were conducted by the numerical model, the results of numerical simulation were highly consistent with the experimental test. It indicated that the numerical model and analysis method applied in this study were generally satisfactory.

(6) Seismic behavior: On one hand, under the action of rare earthquake of 8 degree, the severe damage occurred on the model, but the model structure did not collapse, which showed that the safety of the model structure could be guaranteed and the seismic behavior was good. On the other hand, since there was serious damage on the model, the impact of vertical earthquake should not be ignored.

\section{Declarations}

Acknowledgments This work was financially supported by the National Natural Science Foundation of China (Grant No. 52078410). The authors wish to acknowledge the support of Northwest Electric Power Design Institute Co., Ltd. of China Power Engineering Consulting Group for providing the project funds (Grant No. 2017133) and Innovation Team of Xi'an University of Architecture and Technology are also acknowledged.

Funding: National Natural Science Foundation of China (Grant No. 52078410).

Employment: All authors confirm that there is no employment relationship.

Competing Interests: The authors declare that they have no known competing financial interests or personal relationships that could have appeared to influence the work reported in this paper.

\section{Authors' contribution statements:}

Jiarui Li: Formal analysis, Writing - Original Draft.

Guoliang Bai: Methodology, Supervision.

Bin Hao: Investigation, Data Curation.

Shengjie Peng and Yanyu Lang: Investigation, Resources, Validation.

Yazhou Xu: Writing - Review \& Editing.

\section{References}


1. Lotfabadi P (2015) Solar Considerations in High-rise Buildings. Energy Build 89:183-195

2. Azoumah Y, Ramdé EW, Tapsoba G, S.Thiam (2010) Siting guidelines for concentrating solar power plants in the Sahel: Case study of Burkina Faso. Sol Energy 84(8):1545-1553

3. Dominik Heide L, von Bremen M, Greiner et al (2010) Seasonal optimal mix of wind and solar power in a future, highly renewable Europe. Renew Energy 35(11):2483-2489

4. V.Zare M, Hasanzadeh (2016) Energy and exergy analysis of a closed Brayton cycle-based combined cycle for solar power tower plants. Energy Conv Manag 128(15):227-237

5. leva Pakere D Blumberga (2020) Solar power or solar heat: What will upraise the efficiency of district heating? Multi-criteria analyses approach. Energy 198:1-14

6. Behar O, Khellaf A, Mohammedi K. Renewable (2013) A Review of Studies on Central Receiver Solar Thermal Power Plants[J]. \& Sustainable Energy Reviews 23(04):12-39

7. Zhang HY, Zhang LJ, Wang HJ et al (2018) Influences of the duration and frequency content of ground motions on the seismic performance of high-rise intake towers. Eng Fail Anal 91:481-495

8. Lu X, Wang B, Jiang $\mathrm{H}$ et al (2013) Shaking table tests on a complex high-rise structure with two towers and lapping transfer columns. j Earthq Tsunami 07(04):1250030

9. Hariri-Ardebili MA, Rahmani-Samani H, Mirtaheri M (2014) Seismic Stability Assessment of a High-Rise Concrete Tower Utilizing Endurance Time Analysis. Int J Struct Stab Dy 14(06):1450016

10. Guo W, Zhai Z, Wang H et al (2019) Shaking table test and numerical analysis of an asymmetrical twintower super high-rise building connected with long-span steel truss. Struct Des Tall Buil 28(13):e1630.1e1630.27

11. Furukawa S, Sato E, Shi Y et al (2013) Full-scale shaking table test of a base-isolated medical facility subjected to vertical motions. Earthq Eng Struct Dyn 42(13):1931-1949

12. Abdollahiparsa $H$, Homami P, Khoshnoudian $F$ (2016) Effect of vertical component of an earthquake on steel frames considering soil-structure interaction. KSCE J Civ Eng 20(7):2790-2801

13. Harrington CC, Liel AB (2016) Collapse assessment of moment frame buildings, considering vertical ground shaking. Earthq Eng Struct Dyn 45(15):2475-2493

14. Bruneau M (1998) Performance of steel bridges during the 1995 Hyogoken-Nanbu (Kobe, Japan) earthquake-a North American perspective. Eng Struct 20(12):1603-1078

15. Scawthorn C, Yanev PI (1995) 17 January 1995, Hyogo-ken Nambu. Japanese earthquake Eng Struct 17(3):146-157

16. Adalier K, Aydingun $O$ (2001) Structural engineering aspects of the June 27, 1998 Adana-Ceyhan (Turkey) earthquake. Eng Struct 23:343-355

17. Sezen H, Whittaker AS, Elwood KJ, Mosalam KM (2003) Performance of reinforced concrete buildings during the August 171999 Kocaeli, Turkey earthquake, and seismic design and construction practice in Turkey. Eng Struct 25:103-114

18. Doğangün A (2004) Performance of reinforced concrete buildings during the May 1, 2003 Bingöl Earthquake in Turkey. Eng Struct 26(6):841-856

19. Penzien J, Watabe M (1974) Characteristics of 3-dimensional earthquake ground motions. Earthq Eng Struct Dyn 3(4):365-373 
20. Lin YK, Shih T-Y (1981) Vertical seismic load effect on building response. J Eng Mech Div ASCE 107(EM2):331-343

21. Shih T-Y, Lin YK (1982) Vertical seismic load effect on hysteretic columns. J Eng Mech Div ASCE 108(EM2):242-254

22. Elnashai AS, Papazoglou AJ (1996) Analytical and field evidence of the damaging effects of vertical earthquake ground motion. Earthq Eng Struct Dyn 25:1109-1137

23. Elnashai AS, Papazoglou AJ (1997) Procedure and spectra for analysis of RC structures subjected to strong vertical earthquake. J Earthq Eng 1(1):121-155

24. Button MR, Cronin CJ, R.L (2002) Mayes. Effect of vertical motions on seismic response of highway bridges. J Struct Eng 128(12):1551-1564

25. Elgamal A, He L (2004) Vertical earthquake ground motion records: an overview. J Earthq Eng 8(5):663697

26. Di Sarno L, Elnashai AS, Manfredi G (2011) Assessment of RC columns subjected to horizontal and vertical ground motions recorded during the 2009 L'Aquila (Italy) earthquake. Eng Struct 33:1514-1535

27. Bozorgnia Y, Campbell KW (2016) Ground motion model for the vertical-to-horizontal (V/H) ratios of PGA, PGV, and response spectra. Earthq Spectra 32(2):951-978

28. Miguel A, Jaimes, Jorge Ruiz-García (2019) New vertical-to-horizontal ratio spectrum due to intraslab earthquakes for soft-soil sites of Mexico City. Soil Dyn Earthq Eng 126:1-6

29. Rinaldin G, Fasan M, Noé, Salvatore et al (2019) The influence of earthquake vertical component on the seismic response of masonry structures. Eng Struct 185:184-193

30. Felice C (2020) Effect of earthquake statistically correlated vertical component on inelastic demand to regular reinforced-concrete frames. Eng Struct 211:1-17

31. Chen JY, Zhou J, Ma HC et al (2005) Study on model test of high-rise chimney subjected to vertical seismic action. J Build Struct 26(2):87-93

32. Jin YL, Wu TX, Li ZG (2012) Shaking table tests and numerical analysis for vertical seismic response of quayside container cranes. Int J Struct Stab Dy 12(05):1250034

33. Yu ZW, Liu HY, Guo W et al (2014) Shaking Table Test Research on Station Hall Structure of High-speed Railway Station under Vertical Earthquake Excitation. J Dis Prevent Mi Eng 34(04):443-450

34. Sami A, Alshurafa D Polyzois (2018) An experimental and numerical study into the development of FRP guyed towers. Compos Struct 201:779-790

35. Polyzois DJ, Raftoyiannis IG, Ungkurapinan N (2009) Static and dynamic characteristics of multi-cell jointed GFRP wind turbine towers. Compos Struct 90(1):34-42

36. Yu QQ, Gu XL, Li Y, et a (2016) Collapse-resistant performance of super-large cooling towers subjected to seismic actions. Eng Struct 108:77-89

37. Huang XY, Zhou FL, Jin JM et al (2010) Shaking Table Test of Guangzhou New TV Tower. J Civ Eng 43(8):21-29

38. Pratesi F, Sorace S, Terenzi G (2014) Analysis and mitigation of seismic pounding of a slender R/C bell tower. Eng Struct 71:23-34 
39. Gurkalo F, Du YG, Poutos K et al (2017) The nonlinear analysis of an innovative slit reinforced concrete water tower in seismic regions. Eng Struct 134:138-149

40. Piotr Adam, Bońkowski, Zembaty Z et al (2018) Time history response analysis of a slender tower under translational-rocking seismic excitations. Eng Struct 155:397-393

41. Harris HG, Sabnis GM, White RN et al (1983) Structural modeling and experimental techniques. Prenticehall, Englewood Clifs

42. Zhou Y, Lu XL (2012) Method and technology for shaking table model test of building structures. Science Press, Beijing, pp 9-20

43. Lu X, Chen Y, Mao Y (2012) Shaking table model test and numerical analysis of a super tall building with high-level transfer storey. The Structural Design of Tall Special Buildings 21(10):699-723

44. GB 50011-2010 (2016) Code for seismic design of buildings, National Standards of the People's Republic of China. China Architecture \& Building Press, China

45. JGJ/T 101-2015. Specification for seismic test of buildings, National Standards of the People's Republic of China, China Architecture \& Building Press, China

46. Papagiannopoulos GA, Hatzigeorgiou GD (2011) On the use of the half-power bandwidth method to estimate damping in building structures. Soil Dynamics Earthquake Engineering 31(7):1075-1079

47. Li QS, Zhi LH, Tuan AY et al (2011) Dynamic Behavior of Taipei 101 Tower: Field Measurement and Numerical Analysis. J Struct Eng 137(1):143-155

48. GB 50009-2012. Load code for the design of building structures, National Standards of the People's Republic of China, China Architecture \& Building Press, China

\section{Tables}


Table 1

Similarity ratios for shaking table test

\begin{tabular}{|c|c|c|c|}
\hline Parameter & Formula & Similarity ratio & Remark \\
\hline Stress & $\mathrm{S}_{\sigma}$ & $1 / 3$ & Controlling factor \\
\hline Elastic modulus & $\mathrm{S}_{\mathrm{E}}$ & $1 / 3$ & \\
\hline Strain & $S_{\sigma} / S_{E}$ & 1 & \\
\hline Density & $\mathrm{S}_{\sigma} /\left(\mathrm{S}_{\square} \cdot \mathrm{S}_{\mathrm{I}}\right)$ & $8 / 3$ & \\
\hline Mass & $S_{\sigma} \cdot S_{\mid}^{2} / S_{\square}$ & $1 / 2187$ & \\
\hline Length & $\mathrm{S}_{1}$ & $1 / 18$ & Controlling factor \\
\hline Displacement & $\mathrm{S}_{\text {I }}$ & $1 / 18$ & \\
\hline Angle displacement & $S_{\sigma} / S_{E}$ & 1 & \\
\hline Concentrated force & $\mathrm{S}_{\sigma} \cdot \mathrm{S}_{\mathrm{I}}^{2}$ & $1 / 972$ & \\
\hline Moment & $\mathrm{S}_{\sigma} \cdot \mathrm{S}_{\mathrm{I}}^{3}$ & $1 / 17496$ & \\
\hline Period & $\mathrm{S}_{\mid}{ }^{0.5} \cdot \mathrm{S}_{\square}-0.5$ & 0.157 & \\
\hline Frequency & $\mathrm{S}_{\mid}^{-0.5} \cdot \mathrm{S}_{\square}^{0.5}$ & 6.364 & \\
\hline Acceleration & $\mathrm{S}_{\square}$ & 2.25 & Controlling factor \\
\hline
\end{tabular}

Table 2

Mechanical properties

\begin{tabular}{|lllll|}
\hline Structure & Materials & Compressive strength & Ultimate tensile strength & Elastic modulus \\
\hline Prototype & Ordinary Concrete & $29.6 \mathrm{MPa}$ & - & $33500 \mathrm{MPa}$ \\
\cline { 2 - 5 } & Steel & - & $630 \mathrm{MPa}$ & $206000 \mathrm{MPa}$ \\
\hline Model & Microconcrete & $15.2 \mathrm{MPa}$ & - & $16100 \mathrm{MPa}$ \\
\cline { 2 - 5 } & Red copper & - & $231 \mathrm{MPa}$ & $99000 \mathrm{MPa}$ \\
\hline
\end{tabular}


Table 3

Geometry dimensions of concrete cylinder

\begin{tabular}{|lllll|}
\hline Height(m) & Outer diameter(mm) & Inner diameter(mm) & Wall thickness(mm) & Remark \\
\hline $10.670-11.290$ & 555 & 510 & 45 & \\
10.670 & 555 & 510 & 45 & Boundary section \\
\hline $6.560-10.670$ & 555 & 530 & 25 & Boundary section \\
\hline 6.560 & 555 & 520 & 35 & 35 \\
\hline $1.860-6.560$ & $638-555$ & $593-520$ & 45 & 45 \\
\hline $1.020-1.860$ & & & & \\
\hline $0-1.020$ & 638 & 593 & 55 & \\
\hline
\end{tabular}

Table 4 Reinforcement design in concrete cylinder

\begin{tabular}{|llll|}
\hline Height $(\mathrm{m})$ & $\begin{array}{l}\text { Longitudinal } \\
\text { reinforcement }\end{array}$ & $\begin{array}{l}\text { Circumferential inner } \\
\text { reinforcement }\end{array}$ & $\begin{array}{l}\text { Circumferential outer } \\
\text { reinforcement }\end{array}$ \\
\hline $\begin{array}{l}10.670- \\
11.290\end{array}$ & 2D1.6@20 & 1D1.6@10 & 1D1.6@10 \\
\hline $\begin{array}{l}6.560- \\
10.670\end{array}$ & 1D1.6@20 & 1D1.2@10 & - \\
\hline $1.860-6.560$ & 2D1.6@20 & 1D1.2@20 & 1D1.2@20 \\
\hline $0-1.860$ & 2D2.1@20 & 1D1.2@20 & 1D1.2@20 \\
\hline
\end{tabular}

Note: " $D$ " is the diameter of the galvanized iron, the diameter of $14^{\#}, 16^{\#}, 18^{\#}$ are $2.1 \mathrm{~mm}, 1.6 \mathrm{~mm}, 1.2 \mathrm{~mm}$.

Table 5 Test conditions 


\begin{tabular}{|c|c|c|c|c|c|c|}
\hline \multirow[t]{2}{*}{ Sequence } & \multirow[t]{2}{*}{ Seismic intensity } & \multicolumn{3}{|l|}{$P G A / g$} & \multirow[t]{2}{*}{ Seismic wave } & \multirow{2}{*}{$\begin{array}{l}\text { Test } \\
\text { name }\end{array}$} \\
\hline & & $x$ & $\mathrm{Y}$ & Z & & \\
\hline 1 & \multirow{4}{*}{$\begin{array}{l}\text { Fortification earthquake of } 6 \\
\text { degree }\end{array}$} & 0.030 & 0.030 & 0.030 & White noise & B1 \\
\hline 2 & & - & - & 0.113 & El-Centro & EZ1 \\
\hline 3 & & - & - & 0.113 & Taft & TZ1 \\
\hline 4 & & - & - & 0.113 & $\begin{array}{l}\text { Artificial } \\
\text { wave }\end{array}$ & RZ1 \\
\hline 5 & \multirow[t]{4}{*}{ Frequent earthquake of 8 degree } & 0.030 & 0.030 & 0.030 & White noise & B2 \\
\hline 6 & & - & - & 0.158 & El-Centro & EZ2 \\
\hline 7 & & - & - & 0.158 & Taft & TZ2 \\
\hline 8 & & - & - & 0.158 & $\begin{array}{l}\text { Artificial } \\
\text { wave }\end{array}$ & RZ2 \\
\hline 9 & \multirow{4}{*}{$\begin{array}{l}\text { Fortification earthquake of } 7 \\
\text { degree }\end{array}$} & 0.030 & 0.030 & 0.030 & White noise & B3 \\
\hline 10 & & - & - & 0.225 & El-Centro & EZ3 \\
\hline 11 & & - & - & 0.225 & Taft & TZ3 \\
\hline 12 & & - & - & 0.225 & $\begin{array}{l}\text { Artificial } \\
\text { wave }\end{array}$ & RZ3 \\
\hline 13 & \multirow[t]{5}{*}{ Rare earthquake of 8 degree } & 0.030 & 0.030 & 0.030 & White noise & B4 \\
\hline 14 & & 0.900 & 0.765 & 0.585 & El-Centro & EXYZ \\
\hline 15 & & 0.900 & 0.765 & 0.585 & Taft & TXYZ \\
\hline 16 & & 0.900 & 0.765 & 0.585 & $\begin{array}{l}\text { Artificial } \\
\text { wave }\end{array}$ & $\mathrm{RXYZ}$ \\
\hline 17 & & 0.030 & 0.030 & 0.030 & White noise & B5 \\
\hline
\end{tabular}

Note: "6 degree, 7 degree, 8 degree" represent the seismic intensity defined by Chinese specification [44]. 
Table 6

Parameters of the shake table

\begin{tabular}{|ll|}
\hline Platform size & $4.1 \mathrm{~m} \times 4.1 \mathrm{~m}$ \\
\hline Maximum payload & $20 \mathrm{t}$ \\
$\begin{array}{l}\text { Maximum overturning } \\
\text { moment }\end{array}$ & $80 \mathrm{t} \cdot \mathrm{m}$ \\
\hline Frequency range & $0.1 \sim 50 \mathrm{~Hz}$ \\
\hline Maximum displacement & $\pm 15 \mathrm{~cm}(X$ direction $), \pm 25 \mathrm{~cm}(Y$ direction $), \pm 10 \mathrm{~cm}(Z$ direction $)$ \\
\hline Maximum velocity & $\pm 100 \mathrm{~cm} / \mathrm{s}(X$ direction $), \pm 125 \mathrm{~cm} / \mathrm{s}(Y$ direction $), \pm 80 \mathrm{~cm} / \mathrm{s}(Z$ direction \\
\hline Maximum acceleration & $1.5 \mathrm{~g}(X$ direction $), 1.0 \mathrm{~g}(Y$ and $Z$ direction $)$ \\
\hline
\end{tabular}

Table 7 The natural frequencies and damping ratios

\begin{tabular}{|lllll|}
\hline \multirow{2}{*}{$\begin{array}{l}\text { Test } \\
\text { name }\end{array}$} & \multicolumn{2}{l}{ Natural frequencies $(\mathrm{Hz})$} & \multirow{2}{*}{ Damping ratio } \\
\cline { 2 - 4 } & First-order & Second-order & Third-order & \\
\hline B1 & 18.55 & 20.12 & 22.14 & 0.045 \\
\hline B2 & 18.53 & 19.97 & 22.09 & 0.047 \\
\hline B3 & 18.19 & 19.14 & & \\
\hline B4 & 17.14 & 18.46 & 20.31 & 0.057 \\
\hline B5 & 16.04 & 17.38 & 19.31 & 0.065 \\
\hline
\end{tabular}


Table 8

The maximum acceleration of model structure

\begin{tabular}{|lllll|}
\hline Height $(\mathrm{m})$ & \multicolumn{4}{l}{ Maximum acceleration (Z direction, $\mathrm{g}$ ) } \\
\cline { 2 - 4 } & $\mathrm{PGA}=\mathbf{0 . 1 1 3 g}$ & $\mathrm{PGA}=\mathbf{0 . 1 5 8 g}$ & $\mathrm{PGA}=\mathbf{0 . 2 2 5 g}$ & PGA=0.900g \\
\hline 13.500 & 0.240 & 0.325 & 0.448 & 1.398 \\
\hline 12.760 & 0.515 & 0.592 & 0.426 & 2.269 \\
\hline 11.950 & 0.415 & 0.467 & 0.339 & 1.961 \\
\hline 11.290 & 0.252 & 0.303 & 0.437 & 1.303 \\
\hline 11.000 & 0.099 & 0.108 & 0.169 & 1.282 \\
\hline 10.000 & 0.236 & 0.312 & 0.637 & 1.214 \\
\hline 8.000 & 0.647 & 0.867 & 1.281 & 2.918 \\
\hline 6.000 & 0.627 & 0.842 & 1.246 & 2.837 \\
\hline 4.000 & 0.653 & 0.872 & 1.289 & 2.935 \\
\hline 2.000 & 0.642 & 0.859 & 1.27 & 2.892 \\
\hline 0.000 & 0.176 & 0.222 & 0.303 & 0.761 \\
\hline
\end{tabular}

Table 9

The Maximum vertical displacement

\begin{tabular}{|lllll|}
\hline Height $(\mathrm{m})$ & \multicolumn{3}{l|}{ Maximum displacement (Z direction, $\mathrm{mm}$ ) } \\
\cline { 2 - 4 } & PGA=0.158g & PGA=0.225g & PGA=0.900g \\
\hline 13.500 & 0.41 & 0.55 & 0.76 & 2.36 \\
\hline 11.290 & 0.43 & 0.51 & 0.74 & 2.20 \\
\hline 11.000 & 0.17 & 0.18 & 0.29 & 2.17 \\
\hline 7.000 & 1.06 & 1.26 & 2.11 & 4.79 \\
\hline 4.000 & 1.10 & 1.47 & 2.18 & 4.96 \\
\hline 0.000 & 0 & 0 & 0 & 0 \\
\hline
\end{tabular}

Table 10 The maximum vertical seismic force 


\begin{tabular}{|c|c|c|c|c|}
\hline \multirow[t]{2}{*}{ Height (m) } & \multicolumn{4}{|c|}{ The vertical seismic force $(\mathrm{kN})$} \\
\hline & $0.113 \mathrm{~g}$ & $0.158 \mathrm{~g}$ & $0.225 \mathrm{~g}$ & $0.900 \mathrm{~g}$ \\
\hline 13.500 & 0.20 & 0.20 & 0.40 & 1.10 \\
\hline 12.760 & 1.20 & 2.30 & 0.90 & 6.20 \\
\hline 11.950 & 1.40 & 2.80 & 1.10 & 7.80 \\
\hline 11.000 & 0.50 & 1.50 & 0.90 & 7.50 \\
\hline 10.000 & 3.00 & 3.60 & 7.50 & 15.90 \\
\hline 8.000 & 12.90 & 15.10 & 26.80 & 62.20 \\
\hline 6.000 & 17.10 & 20.00 & 35.60 & 82.60 \\
\hline 4.000 & 24.30 & 28.30 & 50.40 & 116.90 \\
\hline 2.000 & 30.30 & 35.20 & 62.80 & 145.60 \\
\hline 0.000 & 10.70 & 12.20 & 21.30 & 49.50 \\
\hline
\end{tabular}

Table 11. The parameters of the finite element model 


\begin{tabular}{|llllll|}
\hline Material & Concrete & Copper & $\begin{array}{l}\text { Galvanized } \\
\text { wire }\end{array}$ & $\begin{array}{l}\text { Concrete Damage Plasticity } \\
\text { Model }\end{array}$ \\
\hline Density & $4500 \mathrm{~kg} / \mathrm{m}^{3}$ & $8920 \mathrm{~kg} / \mathrm{m}^{3}$ & $7850 \mathrm{~kg} / \mathrm{m}^{3}$ & Dilatancy angle & 30 \\
\hline Young's modulus & $16100 \mathrm{MPa}$ & $99000 \mathrm{MPa}$ & $200000 \mathrm{MPa}$ & Eccentricity & 0.1 \\
\hline Poisson's ratio & 0.2 & 0.32 & 0.3 & $\mathrm{~K}_{\mathrm{c}}$ & $2 / 3$ \\
\hline $\begin{array}{l}\text { Compression } \\
\text { strength }\end{array}$ & $15.2 \mathrm{MPa}$ & - & - & $\mathrm{f}_{\mathrm{b} 0} / \mathrm{f}_{\mathrm{c} 0}$ & 1.16 \\
\hline Tensile strength & $1.37 \mathrm{MPa}$ & $231 \mathrm{MPa}$ & $280 \mathrm{MPa}$ & Viscosity parameter & 0.001 \\
\hline
\end{tabular}

Table 12

Natural frequency of test and numerical model

\begin{tabular}{|llll|}
\hline Natural frequency & First mode & Second mode & Third mode \\
\hline Test & 18.55 & 20.12 & 22.14 \\
\hline Numerical model & 19.06 & 21.33 & 23.65 \\
\hline Error & $2.7 \%$ & $6.0 \%$ & $6.8 \%$ \\
\hline
\end{tabular}

Table 13 The seismic action control coefficient

\begin{tabular}{|llllllll|}
\hline Height $(\mathrm{m})$ & PGA=0.113g & \multicolumn{2}{l}{ PGA=0.158g } & PGA=0.225g & \multicolumn{2}{l|}{ PGA=0.900g } \\
\cline { 2 - 8 } & $C_{X}$ & $C_{X}$ & $C_{Y}$ & $C_{X}$ & $C_{Y}$ & $C_{X}$ & $C_{Y}$ \\
\hline 13.70 & 5.00 & 7.00 & 5.00 & 4.25 & 3.50 & 2.00 & 1.91 \\
\hline 13.00 & 2.25 & 1.61 & 1.30 & 5.22 & 4.67 & 1.05 & 1.00 \\
\hline 12.50 & 2.71 & 1.82 & 1.54 & 5.82 & 5.36 & 1.18 & 1.09 \\
\hline 11.00 & 9.80 & 4.40 & 3.80 & 9.33 & 8.78 & 1.67 & 1.55 \\
10.00 & 2.57 & 2.89 & 2.64 & 1.76 & 1.75 & 1.28 & 1.27 \\
\hline 8.00 & 0.86 & 0.93 & 0.83 & 0.65 & 0.64 & 0.50 & 0.46 \\
\hline 6.00 & 0.81 & 0.86 & 0.76 & 0.59 & 0.58 & 0.45 & 0.44 \\
\hline 4.00 & 0.68 & 0.73 & 0.60 & 0.51 & 0.48 & 0.40 & 0.39 \\
\hline 2.00 & 0.65 & 0.67 & 0.53 & 0.46 & 0.43 & 0.39 & 0.36 \\
\hline 0.00 & 2.05 & 2.20 & 1.66 & 1.57 & 1.43 & 1.44 & 1.24 \\
\hline
\end{tabular}


Table 14

Comparison of structural response under vertical earthquake

\begin{tabular}{|c|c|c|c|c|c|c|c|c|c|c|}
\hline \multicolumn{2}{|c|}{ Seismic waves } & \multicolumn{3}{|c|}{$\begin{array}{l}\text { Horizontal } \\
\text { acceleration/g }\end{array}$} & \multicolumn{3}{|c|}{$\begin{array}{l}\text { Horizontal } \\
\text { displacement/mm }\end{array}$} & \multicolumn{3}{|c|}{ Shear force/kN } \\
\hline & & $x$ & $X+Z$ & $\frac{x+Z}{x}$ & $x$ & $X+Z$ & $\frac{x+Z}{x}$ & $x$ & $X+Z$ & $\frac{X+Z}{x}$ \\
\hline \multirow[t]{3}{*}{$0.225 \mathrm{~g}$} & $\begin{array}{l}\text { El- } \\
\text { Centro }\end{array}$ & 1.873 & 1.895 & 1.012 & 20.620 & 22.538 & 1.093 & 31.000 & 31.775 & 1.025 \\
\hline & Taft & 1.972 & 2.015 & 1.022 & 23.780 & 26.467 & 1.113 & 31.600 & 32.042 & 1.014 \\
\hline & Artificial & 1.711 & 1.740 & 1.017 & 19.830 & 21.892 & 1.104 & 33.200 & 33.731 & 1.016 \\
\hline \multirow[t]{3}{*}{$0.495 \mathrm{~g}$} & $\begin{array}{l}\text { El- } \\
\text { Centro }\end{array}$ & 1.956 & 2.030 & 1.038 & 39.770 & 44.463 & 1.118 & 51.100 & 55.852 & 1.093 \\
\hline & Taft & 1.987 & 2.100 & 1.057 & 48.220 & 72.330 & 1.500 & 51.700 & 55.836 & 1.080 \\
\hline & Artificial & 1.913 & 2.286 & 1.195 & 36.980 & 53.510 & 1.447 & 53.600 & 55.154 & 1.029 \\
\hline \multirow[t]{3}{*}{$0.900 \mathrm{~g}$} & $\begin{array}{l}\text { El- } \\
\text { Centro }\end{array}$ & 2.213 & 2.513 & 1.136 & 63.220 & 87.686 & 1.387 & 59.500 & 66.224 & 1.113 \\
\hline & Taft & 2.228 & 2.483 & 1.114 & 71.910 & 111.820 & 1.555 & 61.700 & 74.102 & 1.201 \\
\hline & Artificial & 1.994 & 2.447 & 1.227 & 54.120 & 80.260 & 1.483 & 69.200 & 80.618 & 1.165 \\
\hline
\end{tabular}

\section{Figures}

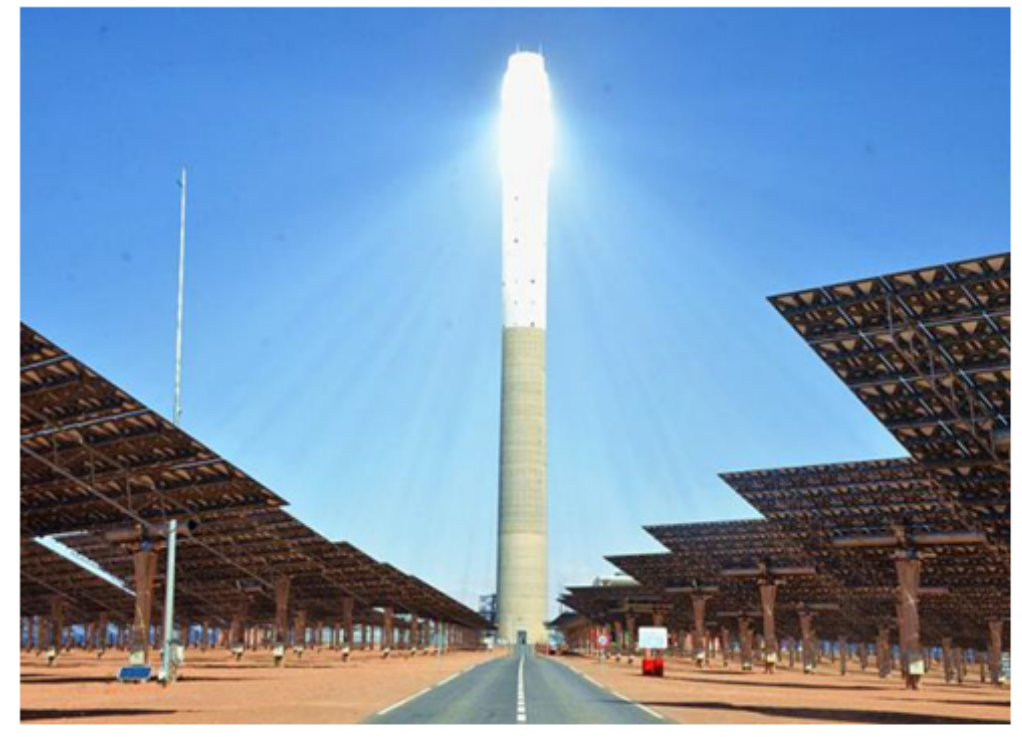

(a)
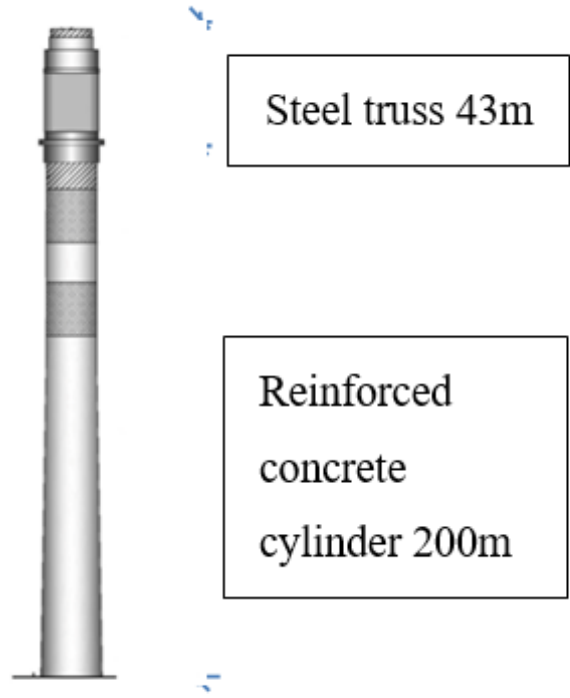

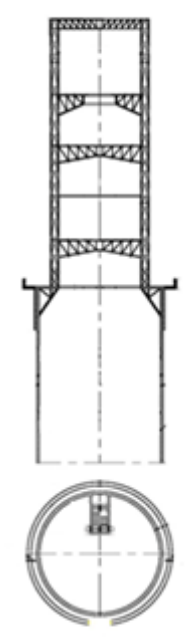

(b)

Figure 1

(a) The prototype structure of the receiver tower (b) The elevation and section views 
Figure 2

Elevation view of model structure

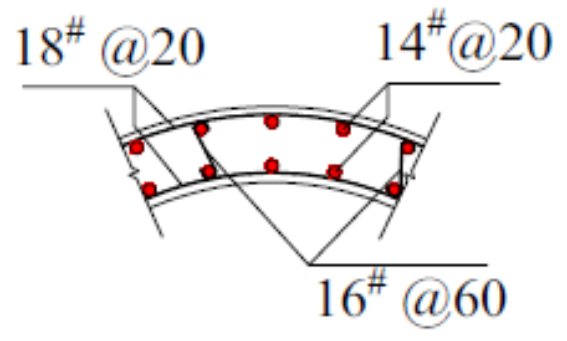

(a) Section 1-1 (0-1.860m)

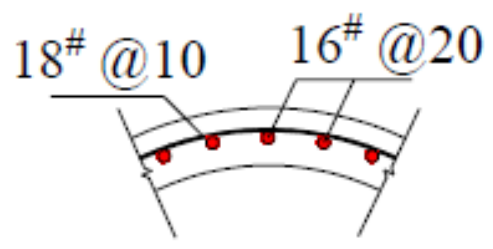

(c) Section 3-3 (6.560-10.670m)

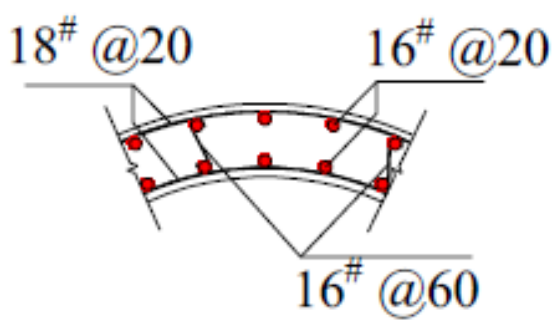

(b) Section 2-2 (1.860-6.560m)

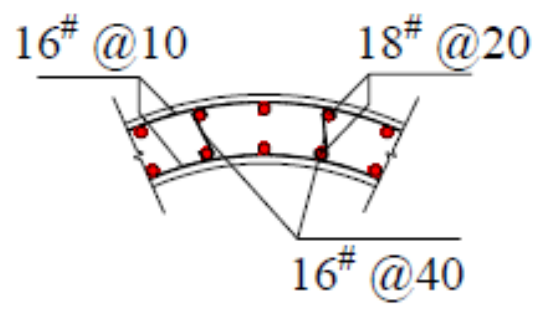

(d) Section 4-4 (10.670-11.290m)

\section{Figure 3}

Reinforcement of concrete cylinder

Figure 4

Longitudinal reinforcement configuration

Figure 5

(a) Plan view of copper structure (b) Elevation view of copper structure

Figure 6

Member types of copper structure 
Figure 7

Copper truss

\section{Figure 8}

Model structure

\section{Figure 9}

(a) El-Centro wave (b) Taft wave (c) Artificial wave

\section{Figure 10}

Acceleration response spectrum

\section{Figure 11}

(a) Acceleration sensors (b) Strain gauges

\section{Figure 12}

Cracks in concrete cylinder ( $P G A=0.158 \mathrm{~g})$

\section{Figure 13}

Cracks in concrete cylinder ( $P G A=0.225 g$ )

\section{Figure 15}

The first-order mode shape in vertical

\section{Figure 16}

Envelope diagrams of acceleration amplification factor of model structure

\section{Figure 17}


Envelope diagrams of vertical displacement

Figure 18

Envelope diagram of the vertical seismic force

Figure 19

The constitutive relation of materials

Figure 20

The whole receiver tower finite element model

Figure 21

The first vertical mode shape

Figure 22

Acceleration response comparison between experimental and numerical simulation under Taft wave

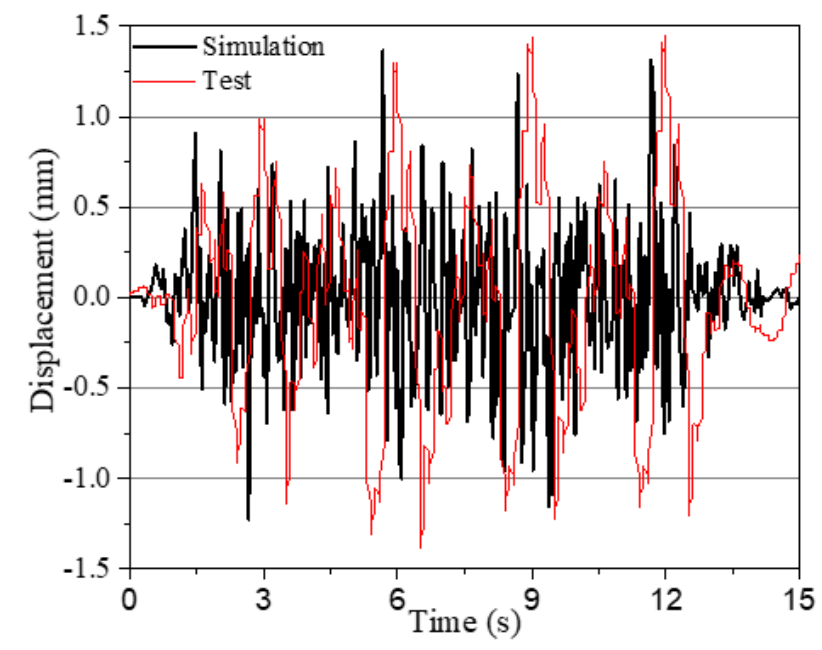

(a) Taft wave (PGA=0.158g)

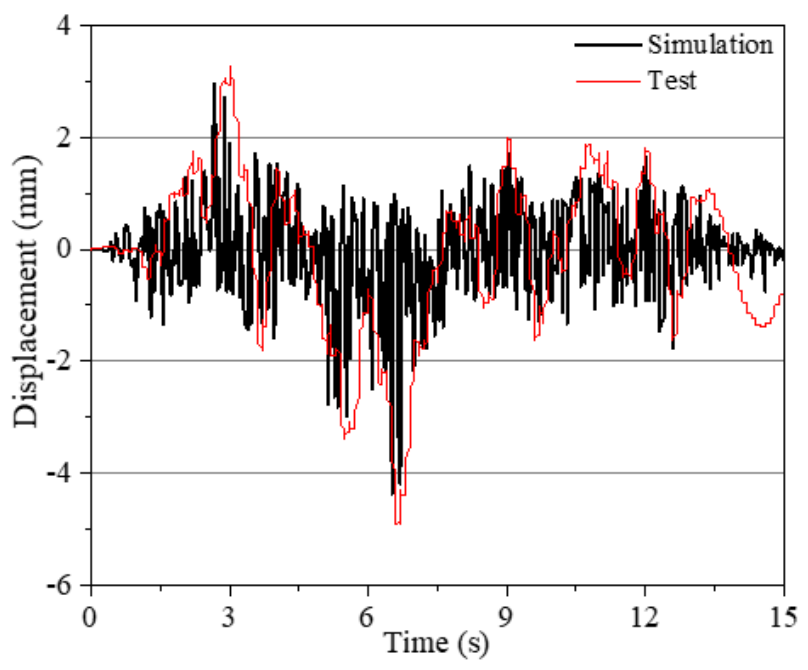

(b) Taft wave (PGA=0.900g)

Figure 23

Displacement response comparison between experimental and numerical simulation under Taft wave 
Figure 24

Vertical seismic force comparison between experimental and numerical simulation under seismic waves

\section{Figure 25}

Damage distribution and stress nephogram of numerical simulation model

\section{Figure 26}

The acceleration under different seismic waves with PGA of $0.900 \mathrm{~g}$

\section{Figure 27}

Increment of seismic responses under $X Z$ earthquakes 